\title{
BIOLOGICAL AND CHEMICAL ASSESSMENT OF WATER HYACINTH (EICHHORNIA CRASSIPES (MART.) SOLMS.) OF PHEWA LAKE, NEPAL
}

\author{
Bikash Baral* and Geeta Shrestha Vaidya* \\ *Nepal Academy of Science and Technology (NAST), Kathmandu, Nepal.
}

\begin{abstract}
Experiments relating to bioassay, phytochemical screening and bio-control of obnoxious aquatic weed i.e., water hyacinth were conducted in Nepal Academy of Science and Technology (NAST) laboratory. Bioassay was performed from the methanolic and aqueous extracts obtained by hot and cold percolation method that. The antibacterial and antifungal effects were performed against 11 clinical bacteria (2 gram positive and 9 gram negative) and 7 phytopathogenic fungi using agar well diffusion method. The pattern of inhibition varied with different extracts and the micro-organism tested. The soxhlet methanolic extract showed activity against $54.45 \%$ of bacteria and $57.14 \%$ fungi while cold methanolic extract showed activity against 45.45 \% bacteria and 42.85\% fungi employed. Similarly, hot aqueous extract showed activity against 18.18\% bacteria and $42.85 \%$ fungi while in cold aqueous extraction, the activity was null and $57.14 \%$ against bacteria and fungi respectively. The methanolic fraction proved more effective than cold aqueous extract showing more antibacterial activity while cold aqueous extract showed comparably better result in different fungi employed. The most susceptible organisms were Klebsiella pneumoniae, Salmonella typhi, Sclerotium rolfsii, and Fusarium moniliforme. Preliminary phytochemical analysis of different extracts revealed the presence of alkaloids, reducing compounds, polyoses and saponins. The GC-MS analysis shows the presence of Phenols and Carotenoids as the bio-active compounds in the test plant. In regards to bio-control, the propagation of this weed was found to be totally checked within 21 days after the application of aqueous lechate of Lantana camara (1-3\%), while that was checked within a month by the supplementation of young twigs powder of Ageratina adenophorum (7\%).
\end{abstract}

Key-words: Antimicrobial activity; Plant extract; ZOI; Phytochemicals; Biocontrol; GC-MS.

\section{INTRODUCTION}

Anti-microbials are the substances that kill (microbiocidal) or inhibit the growth of microorganisms (microbiostatic) such as bacteria, fungi or protozoans. Antimicrobial plant extracts are of enormous value; the phytochemicals present in the plants may pave their way into the arsenal of antimicrobial drugs as prescribed by the physicians. These medicinal plants have received a lot of attention in the pharmaceutical and scientific communities and the various works have been documented for the therapeutic value of natural compounds in a bid to validate claims of their biological activity. Particular focus is on establishing the effect of the plant extracts in terms of their microstatic and microcidal action and the spectrum of organisms affected. This has enabled exploitation of plants for the treatment of microbial infections and in the development of new antimicrobial agents.

Plants have an almost limitless ability to synthesize aromatic substances, most of which are phenols or their oxygensubstituted derivatives. Herbal remedies and alternative medicines are used throughout the world and in the past, herbs often represented the original sources of most drugs (Sa'ad et al., 2005). Despite the tremendous progress in human medicines, infectious diseases caused by fungi, bacteria, viruses and parasites are still a major threat to public health. Their impact is particularly large in developing countries like Nepal due to relative unavailability of medicines and the emergence of widespread drug resistance (Zampini et al ., 2009). Therefore, attention has been drawn to the antimicrobial activity of plants and their metabolism due to the challenge of growing incidences of drug-resistant pathogens.

Water hyacinth [Eichhornia crassipes (Mart.) Solms], fast growing perennial aquatic macrophyte (Reddy and Sutton, 1984) locally called 'Jalkumbhi', is one of the world's most obnoxious waterweeds when not controlled. It is listed as one of the most productive plant on earth and is considered the world's worst aquatic weed. Recently, considerable attention has been given to harvesting this aquatic plant for practical uses to partially defray the cost of removing plants

Author for Correspondence: Bikash Baral, Nepal Academy of Science and Technology (NAST), Kathmandu, Nepal. E-mail: bikubaral@yahoo.com. 
from waterways and use as economical sources in many parts of the world (Lata \& Dubey, 2010). Though very less pharmacological study and biological activity of this plant has been reported, this study was designed to evaluate the phytochemical screening of active substances, antimicrobial assay of the plant extracts in order to establish the molecular basis for some of its therapeutic properties. Also, the biological control of the plant was assessed to remove the weed without difficulty.

\section{MATERIALS AND METHODS}

Sampling: Plant samples of water hyacinth were identified and collected from the Phewa Lake. These were air dried followed by crushing to powder with the aid of grinder. The powdered samples were then employed for extraction in different solvents.

Soxhlet (hot method) extraction in methanol and water: $40 \mathrm{~g}$ of the powder was taken and was placed in the soxhlet apparatus for extraction. Two hundred $\mathrm{ml}$ of respective solvents (i.e. methanol and water) leach was poured in the soxhlet apparatus with temperature rising to $40^{\circ} \mathrm{C}$ and $90^{\circ} \mathrm{C}$ respectively. The experimentation was continued till complete extraction and different concentrations $\left(50 \mathrm{mgml}^{-1}, 100 \mathrm{mgml}^{-1}\right.$, $150 \mathrm{mgml}^{-1}$ and $200 \mathrm{mgml}^{-1}$ ) of working solutions were prepared.

Percentage yield of each extract was calculated by the following formula:

$\%$ yield $=\underline{\text { Weight of extract obtained }} \quad \mathrm{X} 100$

Total weight of the sample loaded

Cold methanolic and aqueous extraction: $40 \mathrm{~g}$ of the powder was left to imbibe overnight in the methanol and water separately and was filtered to obtain the extract and the different concentrations of the extracts (working solution) were prepared.

Bacterial and fungal strains: The different strains of bacteria used were Proteus mirabilis, Salmonella typhi, S. paratyphi, Enterococcus faecalis, Bacillus subtilis, Acinetobacter sp., Klebsiella pneumoniae, Schigella dysenteriae, Staphylococcus aureus, Escherichia coli and Pseudomonas aeruginosa. Similarly, the different phytopathogenic fungi employed for the experiment were Fusarium oxysporum, F. moniliforme, F. proliferatum, F. erundiformae, Sclerotium rolfsii, Exserohilium turticum and Curvularia sp.

Antimicrobial susceptibility testing: Agar well diffusion method was employed to assay the plant extracts for antimicrobial activity. The antibacterial and antifungal assays were performed using Mueller-Hinton Agar (MHA) and Potato Dextrose Agar (PDA) media respectively. The test organisms comparable to standard were spread on to the surface of the media using a sterile swap stick. Cork borer $(6 \mathrm{~mm})$ was used to bore wells in the media. The different concentration of the plant extracts were dispensed (50 $\mu \mathrm{l}$ ) into the wells using a sterile micropipette. These were then allowed a diffusion time of $1 \mathrm{~h}$ after which it was incubated at $37 \pm 1^{\circ} \mathrm{C}$ for $24 \mathrm{~h}$ for antibacterial assay and $27 \pm 1^{\circ} \mathrm{C}$ for $7 \mathrm{~d}$ for antifungal assay.
Diameter of zone of inhibitions was measured for the estimation of potency of the antimicrobial substance and the mean were recorded. Same experimentation was carried out with three replicates. The values of the control (i.e. respective solvents) were carried out and if the zone of inhibition were obtained, they were then deducted from the total value to get the mean ZOI of the extract fraction in the respective bacteria.

Phytochemical assay: The preliminary screening of the chemical constituents of the weed was performed by extracting in different solvents. The phytochemical analysis was performed using the standard phytochemical methods ( Harborne 1998; Aguinaldo et al. 2005). The total compounds were analysed by employing GC-MS at the Forensic Laboratory, Khumaltar, Lalitpur.

Bio-Control of Water hyacinth: The water hyacinth plants were grown on the buckets with different treatments of Lantana camara and Ageratina adenophorum. The excessive growth of water hyacinth populations can be checked by biological, mechanical and chemical control measures. For checking the colonization of the water hyacinth, aqueous lechate of Lantana camara (1-3\%) and powdered leaves of Ageratina adenophorum(1-7\%) were employed in a bucket having the capacity of $10 \mathrm{~L}$. Regular monitoring and counting of the leaves were done at every 4 days interval till the complete senescence of the plant was observed. The final senescence of the plant was confirmed by the death of the cell resulting the failure in plasmolysis.

\section{RESULTS}

The resulting dried extracts gave yield of 3.2\% and $1.79 \%$ in hot and cold methanolic extraction while $8.4 \%$ and $3.9 \%$ in hot and cold aqueous extraction respectively.

Salmonella typhi was found to have the most antibacterial effect (19 mm) in methanolic hot extract followed by Schigella (17 mm) and Staphylococcus aureus (16mm) whereas Proteus mirabilis, Bacillus subtilis, Escherichia coli, Pseudomonas aeruginosa and Enterococcus faecalis did not showed any activity against the same. In cold methanolic extract, Klebsiella pneumoniae showed highest ZOI (11 mm) which is very less as compared to hot extraction.

Similarly, Klebsiella pneumoniae showed the highest inhibition zone (13 mm) in hot aqueous extraction. Escherichia coli showed little less inhibition zone $(11 \mathrm{~mm})$ after $K$. pneumoniae, whereas other bacteria failed to show the effect against different concentrations of the extracts used. No appreciable ZOI was observed with the cold aqueous fraction by any of the tested bacteria.

As compared to the bacterial effect, the fungal pathogens relatively showed more activity against the extract. The hot extract showed the highest ZOI $(13 \mathrm{~mm})$ against $F$. erundiformae, F. moniliforme and Sclerotium rolfsii whereas F. oxysporum, Exserohilum turticum and Curvularia species did not showed any activity. In cold methanolic fraction, Sclerotium rolfsii showed the highest ZOI (15 mm), while F. 
oxysporum, F. erundiformae, Exserohilium turticum and Curvularia species did not show any activity against concentrations of extracts used. In hot and cold aqueous extract, F. moniliforme showed the highest ZOI i.e., $21 \mathrm{~mm}$ and $15 \mathrm{~mm}$ respectively.

The preliminary phytochemical constituents of different

Table 1 : Phytochemical screening of the different fractions of water hyacinth

\begin{tabular}{|clc|}
\hline Extracts obtained in & Test for compounds & Results \\
\hline & Volatile salts & - \\
& Fatty acids & - \\
& Coumarins & - \\
& Hexane & - \\
& Flavon aglycones & + \\
& Alkaloids & - \\
& Emodins & - \\
& Sterols & - \\
\hline \multirow{5}{*}{ Methanol } & Triterpenes & - \\
& Polyphenols & + \\
& Reducing compound & - \\
& Alkaloid salts & - \\
& Glycosides & - \\
& Quinones & - \\
& Anthocyanosides & - \\
& Anthracenosides & - \\
& Coumarin derivatives & + \\
& Flavonic glycosides & + \\
\hline \multirow{6}{*}{ Aqueous } & Polyoses & + \\
& Saponins & \\
\hline
\end{tabular}

fractions revealed the presence of alkaloids, reducing compounds, polyoses and saponins (Table 1).

Two different bioactive compounds Phenols and Carotenoids were recorded from the GC-MS method. Phenolic compounds 4-Methylresorcinol, 2-Methylresorcinol, p-hydroxybenzoic acid and Pyrogallol have been recorded from the plant (Satyakala,1992).

The rapid propagation of the weed was found to be checked by the supplementation of aqueous lechate of Lantana camara (1-3\%). Eventually, the plant died with shedding of the leaves within 21 days and the complete senescence was observed by the failure in plasmolysis of the cell. The powdered leaves of Ageratina adenophorum (3\%) was also found to inhibit the growth of the plant but it was not so effective as the weed's complete cessation took longer period ( about one month) as compared to 21 days taken by Lantana camara application.

\section{DISCUSSION AND CONCLUSION}

Plant substances continue to serve as viable source of drugs for the world population and several plant-based products are in extensive clinical use (Roja \& Rao, 2000). The variation in the effectiveness of the plant extract against different microorganisms depends upon the chemical composition of the extracts and membrane permeability of the microbes for the chemicals and their metabolism. The inhibition produced by the plant extracts against particular organism depends upon various extrinsic and intrinsic parameters.
In view of the problems encountered with water hyacinth, several management strategies such as chemical, physical, biological etc. have to be practiced to control water hyacinth. However, chemical herbicides should be discouraged due to environmental hazards. Physical removal of water hyacinth is also an effective technique but can be applicable only in small areas. Because of the rich diversity of this aquatic plant it is expected that screening and scientific valuation of plant extracts may prove beneficial for the mankind along with the management of the weed.

Based on the results described, we may conclude that the hot extraction in different solvents (basically the methanolic extract) of water hyacinth possess significant antimicrobial activities. Further research to isolate the antioxidant constituents of the plant with high activity should be done which finally paves the way for the production of bioactive agents.

After the initial screening of phytochemicals, more detailed studies of their antibiotic effects should be conducted. At this stage, more specific media can be used and MICs and MBCs can be effectively compared to those of a wider range of currently used antibiotics.

Due to the good antimicrobial properties of water hyacinth, this weed can be used to make the different pharmaceutical products while controlling this weed on the other hand. If a success in controlling this fungus can be made, a tremendous achievement in the field of horticultural science can be gained. The Fusarium fungi have an expansive reach. Fusarium pathogen is a soil-borne fungus that survives as microscopic spores (chlamydospores) which germinate and infect the different plants under favorable conditions. This fungus invades water-conducting tissues of the root and grows upward into leaf petioles and stems of different crops. Fusarium's impact on agriculture and food safety and its growing role in human health have sparked the interest of researchers. As we tested, analyzed, and validated our results, an explanation for Fusarium species toxicity was known: certain Fusarium species may have unique genetic material that may give them the ability to invade a new host. Furthermore, the pathogens can swap chromosomes with one another, passing the power to invade on to fellow Fusarium pathogens. As this plant extract showed the good antifungal properties against Fusarium species this research may help to open an array of avenues in the field of biotechnology, checking wide growing pathogens.

This study paves the way for further attention and research to identify the active compounds responsible for the plant biological activity. Further studies should be undertaken to elucidate the exact mechanism of action by which extracts exert their antimicrobial effect. Awareness of local community should be enhanced incorporating the traditional knowledge with scientific findings. Exploitation of this rapidly growing weed can be done on making the different pharmaceutical products in one hand, while proper management on the other side. 
Antimicrobial properties against different pathogenic organisms

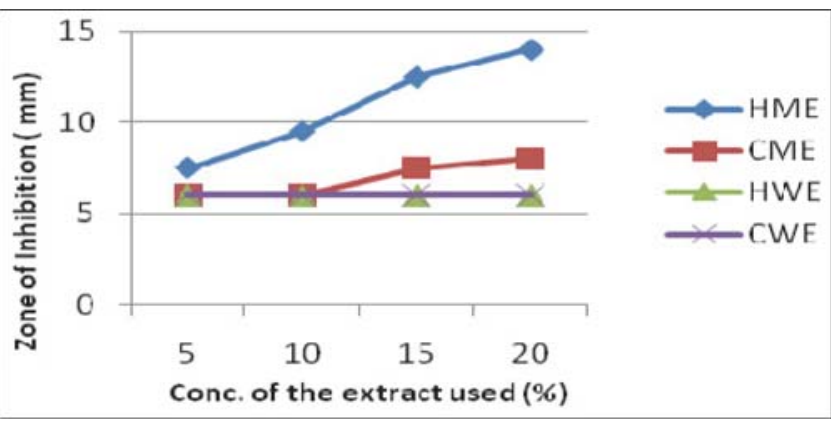

Fig 1: Salmonella paratyphi

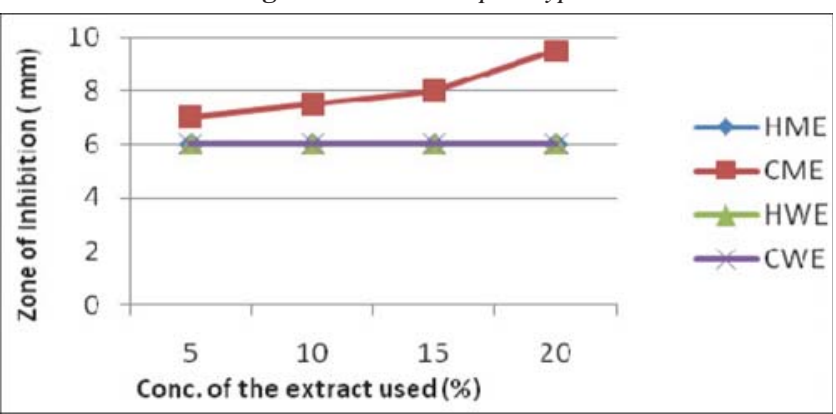

Fig 2: Proteus mirabilis

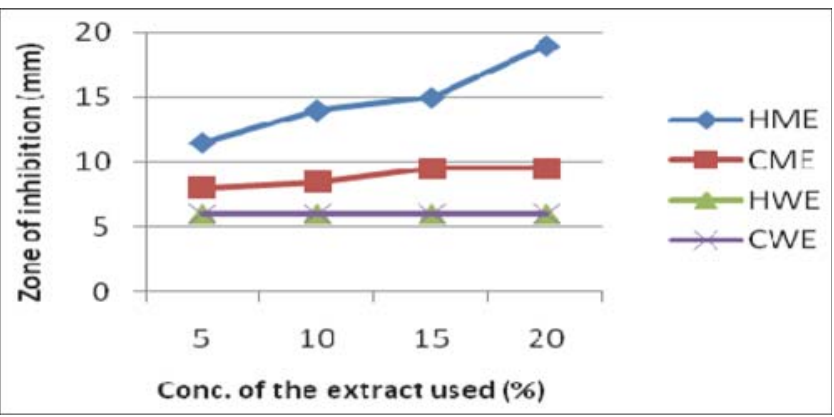

Fig 3: S. typhi

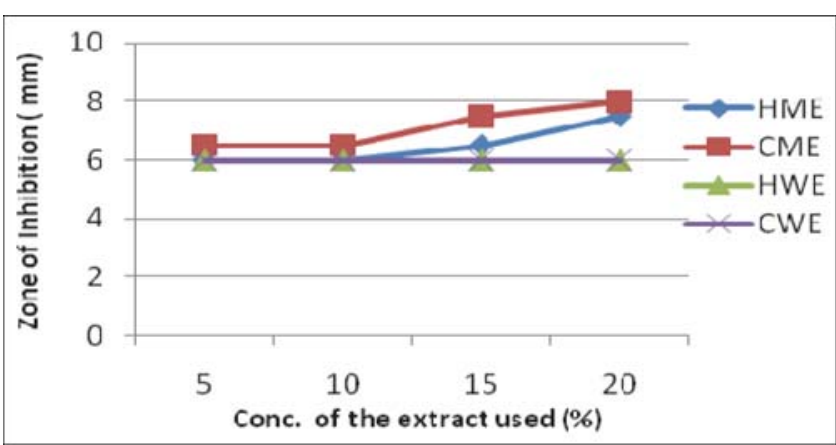

Fig 4: Bacillus subtilis

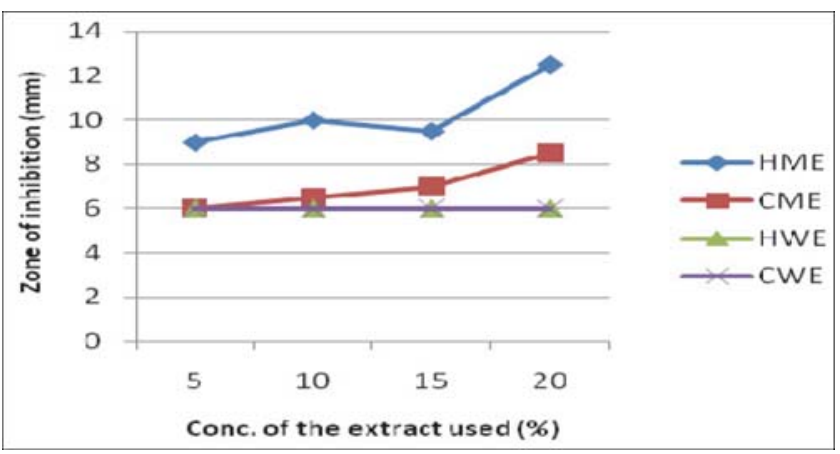

Fig 5: Acinetobacter sp.

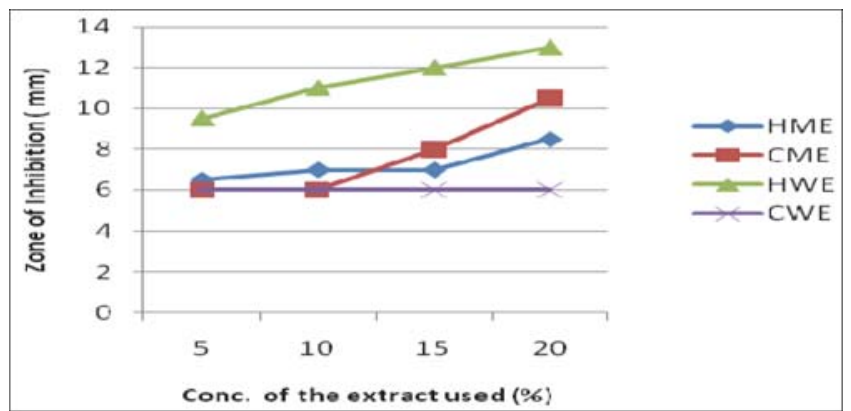

Fig 6: Klebsiella pneumoniae

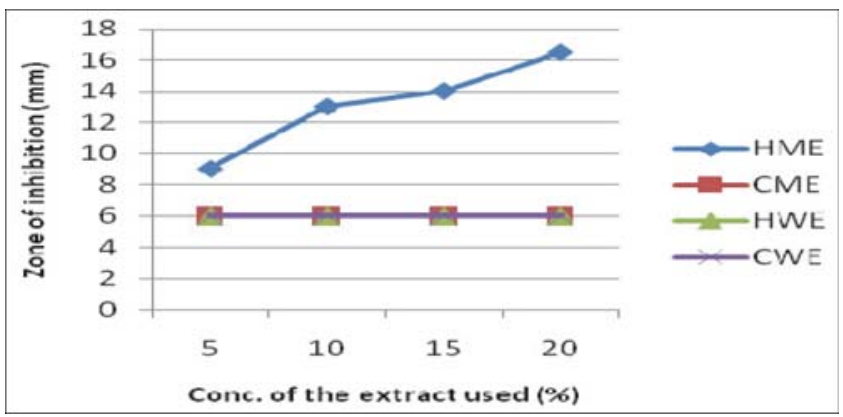

Fig 7: Schigella dysentriae

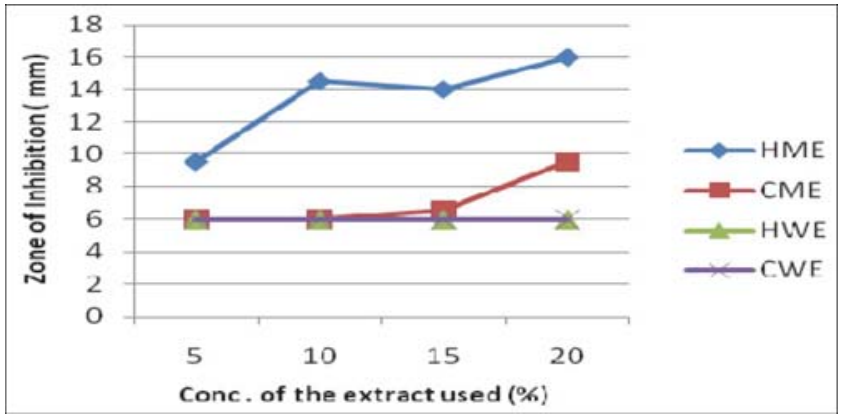

Fig 8: Staphylococcus aureus

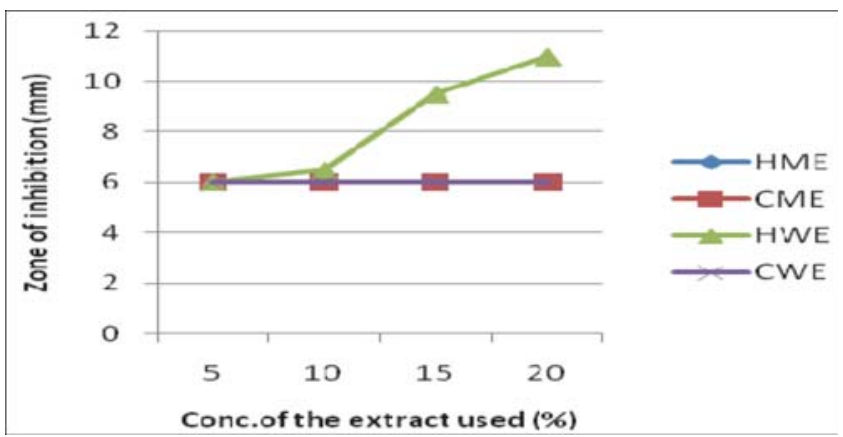

Fig 9: Escherichia coli

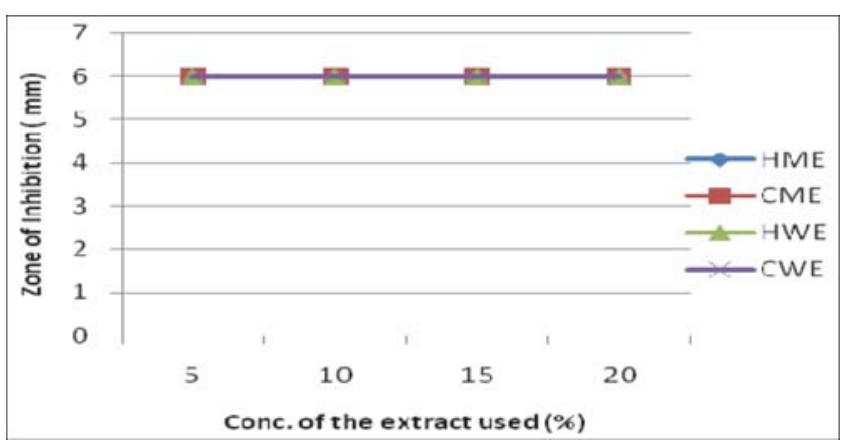

Fig 10: Pseudomonas aeruginosa 


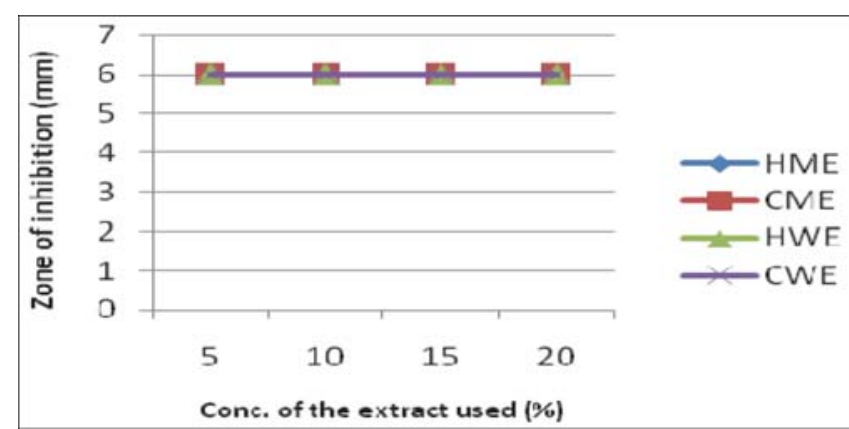

Fig 11: Enterococcus faecalis

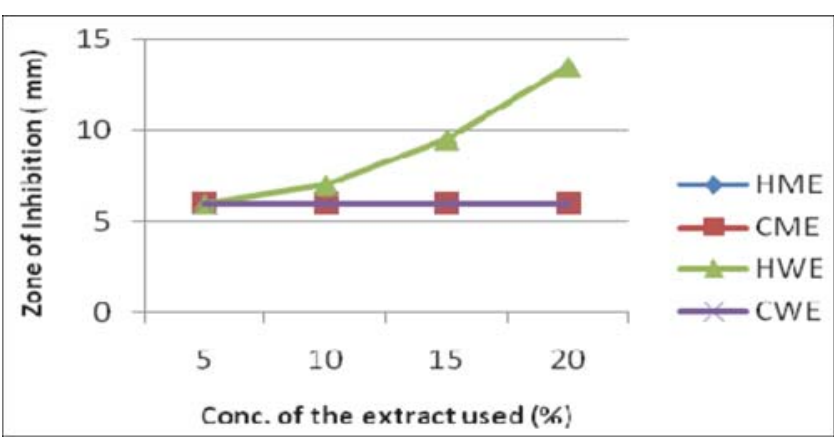

Fig 12: Fusarium oxysporum

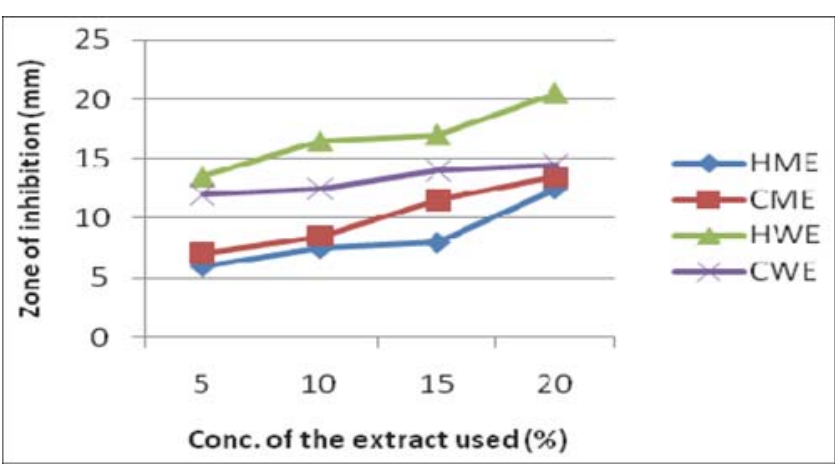

Fig 13: Fusarium moniliforme

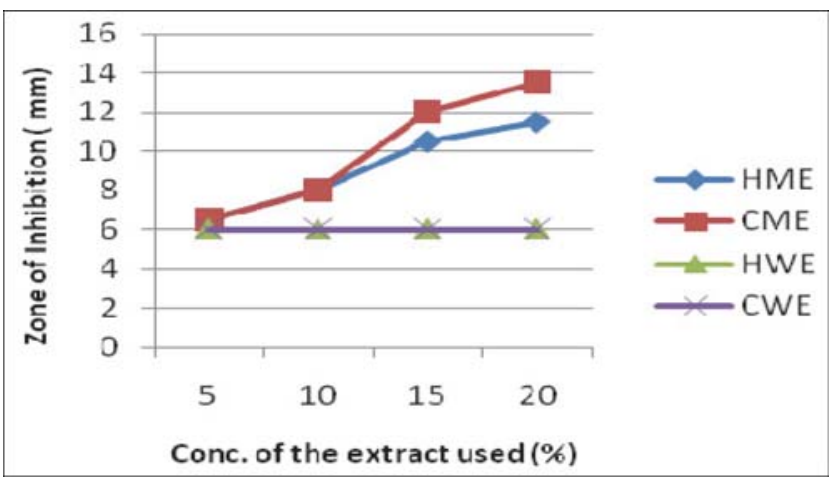

Fig 14: Fusarium proliferatum

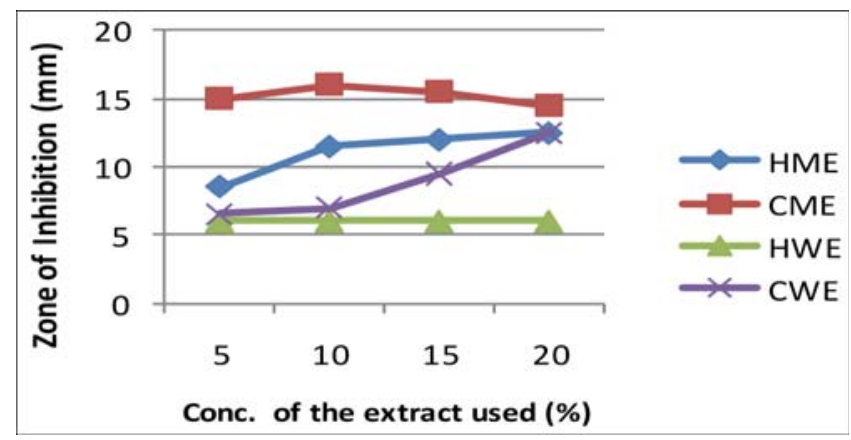

Fig 15: Fusarium erundiformae

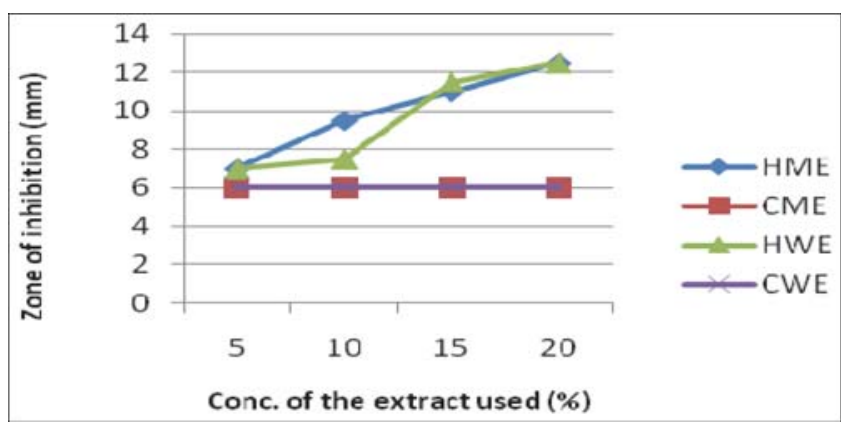

Fig 16: Sclerotium rolfsii

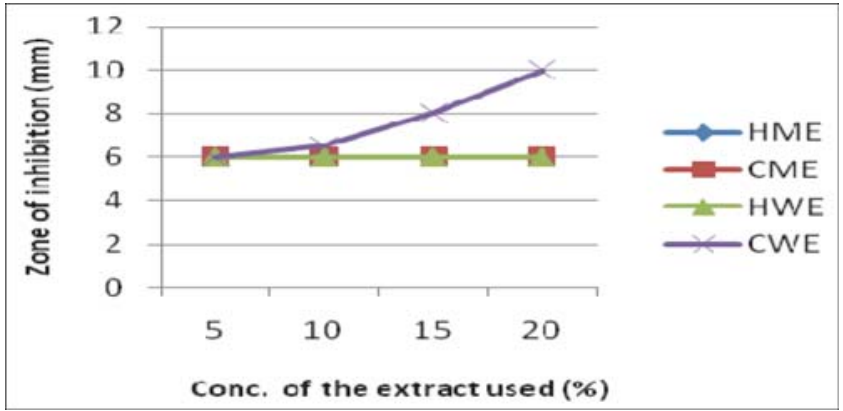

Fig 17: Exserohilium rolfsii

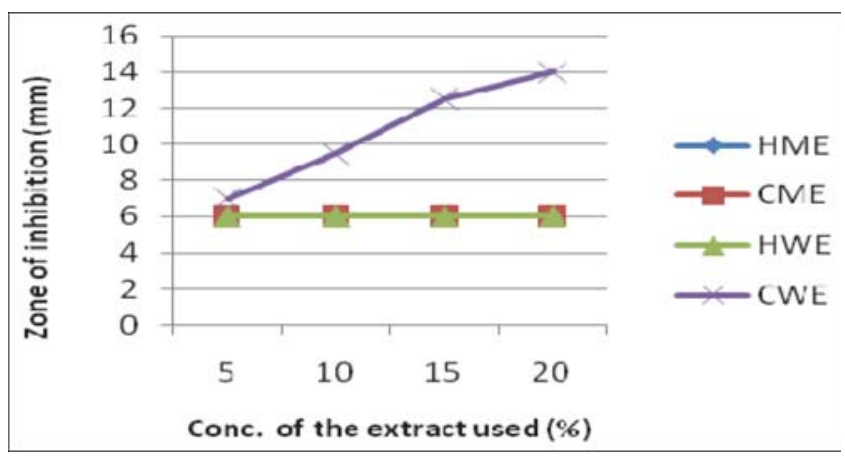

Fig 18: Curvularia sp

HME: Hot methanolic extract; CME: Cold methanolic extract; HWE: Hot aqueous extract; CWE: Cold aqueous extract

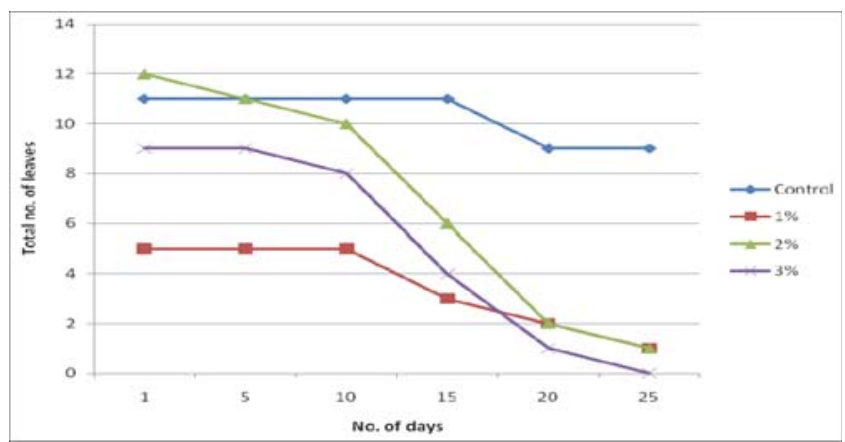

Fig 19: Bio-control of Water hyacinth using Lantana camara

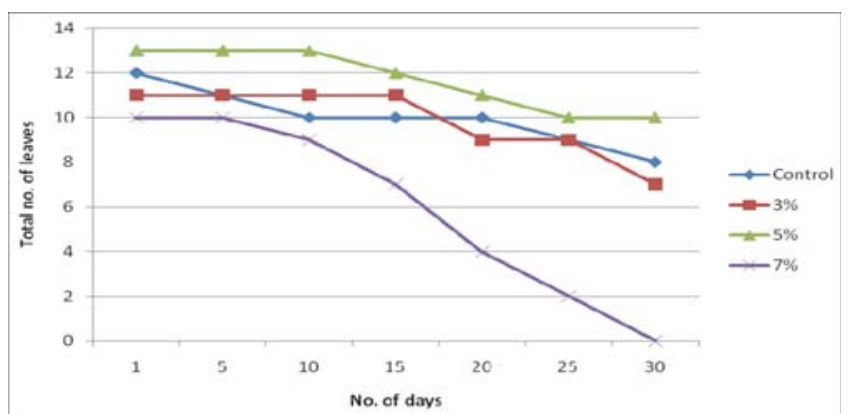

Fig 20: Bio-control of Water hyacinth using Ageratina adenophorum 


\section{Photoplates}

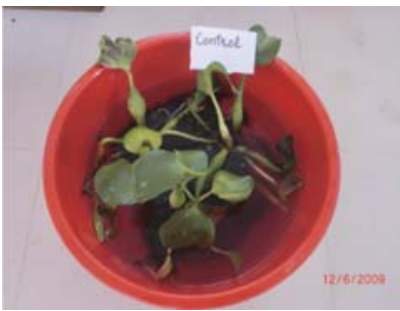

Control

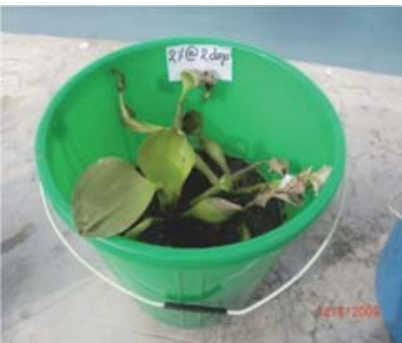

$2 \%$ of Lantana camara at 2 days

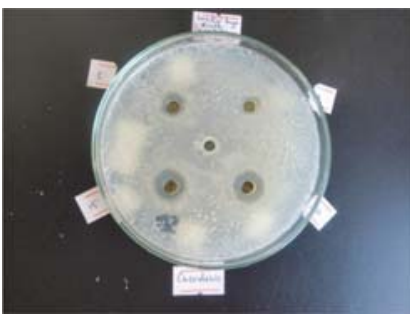

Hot methanolic extract against Curvularia sp.

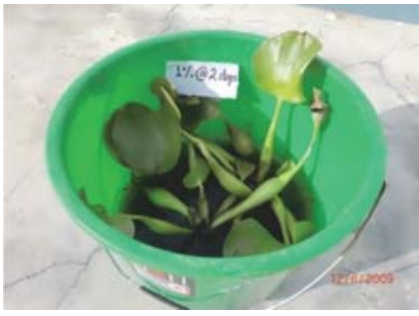

$1 \%$ of Lantana camara at 2 days

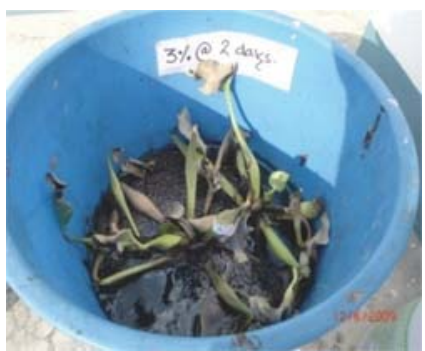

$3 \%$ of Lantana camara at 2 days

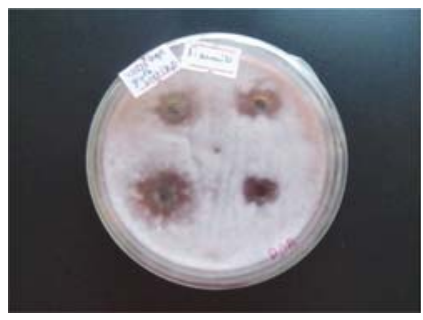

Wet aqueous extract against Fusarium moniliforme

\section{REFERENCES}

Aguinaldo, A.M., Espeso, E.I., Guevara, B.Q. and M.G. 2005. A guidebook to plant screening: Phytochemical and Biological (Ed. B.Q. Guevara) Manila University of Santo Thomas Press, The Philippines.

Center, T.D., Hill, M.P., Cordo, H. and Julien. M.H. 2002. Water hyacinth. In: Van Driesche, R., et al: Biological Control of Invasive Plants in the Eastern United States. USDA Forest Service Publication FHTET-2002-04, 41-64.

Harborne, J.B. 1998. Phytochemical Methods: A Guide to Modern Techniques of Plant Analysis. (3rd edition). Chapman and Hall Co., New York. Pp.1-302.

Lata, N. and Dubey, V. 2010. Isolation of flavonoids from Eichhornia crassipes: The World's worst aquatic plant. Journal of Pharmacy Research. 3(9): 2116-2118.

Reddy, K.R. and Sutton , D.L. 1984: Water hyacinths for Water Quality Improvement and Biomass Production. J. Environ. Quality. 13: 1-8.

Roja, G. and Rao, P.S. 2000. Anticancer compounds from tissue cultures of medicinal plant. J. Herbs Spices Med. Plants. 7: 71-102.

Sa'ad B., Azaizeh, H. and Said, O. 2005. Traditional and perspectives of Arab herbal medicine: A review, Evid Based complements Alternative Medicine. 2: 475 -479.

Satyakala, G. and Jamil, K. 1992. Chromium-Induced Biochemical Changes in Eichhornia crassipes (Mart) Solms and Pistia stratlotes L. Bull. Environ. Contam. Toxicol. 48: 921-928.

U.S. EPA. 1988. Design Manual - Constructed Wetlands and Aquatic Systems for Municipal Wastewater Treatment. U.S. Environmental Protection Agency. Report no. EPA/625/1-88/ 022. Office of Research and Development, Cincinnati, OH, 83.

Zampini, I.C., Cuello, S. , Alberto,M.R., R.M., Almeida, R.D., Solorzano, E. and Isla, M.I. 2009. Antimicrobial activity of selected plant species from "the Argentine Puna" against sensitive and multi-resistant bacteria. Journal of Ethnopharmacology. 124(3): 499-505. 